Departamento de Historia

Universidad de Santiago de Chile

Revista de Historia Social

y de las Mentalidades

Volumen 25, $\mathrm{N}^{\circ} 1,2021: 29-64$

Issn Online: 0719-4749

\title{
MEDICINA DEL TRABAJO Y PREVISIÓN BIOLÓGICA: CONVERSIÓN DE LA ACCIÓN MÉDICA EN LA OBRA POLÍTICA DE EDUARDO CRUZ-COKE LASSABE (CHILE, 1938-1946)*
}

\author{
WORK MEDICINE AND BIOLOGICAL SOCIAL SECURITY: \\ THE CONVERSION OF MEDICAL ACTION IN THE POLITICAL PRODUCTION OF \\ EDUARDO CRUZ-COKE LASSABE (CHILE, 1938-1946)
}

MG. NICOLÁS ANDRÉS CÁRCAMO GEBHARDT**

Institut d'història de la ciència-Unidad de historia de la medicina

Universidad Autónoma de Barcelona

Barcelona, España

Email: nico.carcamo@gmail.com

Id-ORCID: 0000-0001-6350-8563

\begin{abstract}
RESUMEN
Eduardo Cruz-Coke fue una de las figuras más influyentes en la escena médico-política del siglo XX en Chile. Producto de la apreciación de sus propuestas como exentas de funcionalismo económico y de invariable orientación socialcristiana, ha permanecido desvinculado historiográficamente de corrientes emparentadas al determinismo biológico. Esta investigación busca tensionar parte de su obra política mediante el análisis de su programa de "previsión biológica" y "conversión de la acción médica" -vigilancia de los supuestos sanos y detección de morbilidad latente de la clase trabajadora-
\end{abstract}

\begin{abstract}
Eduardo Cruz-Coke was one of the most influential figures of the medical-political panorama of the 20th century in Chile. However, historiographically, he has been disassociated from the currents related to biological determinism. The proposals he developed, far from free economic functionalism and a marked social-Christian orientation, determined this decision. This research seeks to stress part of his political work by analyzing his program of "biological social security" and "conversion of medical action" -surveillance of the supposedly healthy and detection of the latent morbidity of
\end{abstract}

* $\quad$ Recibido: 20 de Diciembre de 2019; Aprobado: 5 de Marzo de 2020.

** $\quad$ Este artículo es producto de la tesis titulada "Medicina del trabajo, vitaminas y la transformación del Salitre en carne: Fundamentos médico-sociales en los discursos políticos de Eduado CruzCoke Lassabe (Chile, 1938-1946)", para optar al grado Master en Historia de la Ciencia, del Centro de Historia de la Ciencia de la Universidad Autónoma de Barcelona, año 2018. 
indagando en lectura respecto a la configuración de un sistema integrado de salud nacional enfocado en lo preventivo.

Palabras clave: Eduardo Cruz-Coke Lassabe; previsión biológica; medicina del trabajo; medicina preventiva the working class- inquiring into the reading regarding the configuration of a national health system integrated and focused on prevention.

Keywords: Eduardo Cruz-Coke Lassabe; Biological Social Security; Work Medicine; Preventive Medicine

Cómo citar: Cárcamo Gebhardt, Nicolás. (2021). "Medicina del trabajo y previsión biológica: Conversión de la acción médica en la obra política de Eduardo Cruz-Coke Lassabe (Chile, 1938-1946)". Revista Historia Social y de las Mentalidades, 25(1), 29-64. https://doi.org/10.35588/rhsm.v25i1.4286

\section{EDUARDO CRUZ-COKE LASSABE. REFLEXIONES SOBRE UN MÉDICO CHILENO}

Durante la primera mitad del siglo XX en Chile, Eduardo Cruz-Coke Lassabe (1899-1974) fue un personaje determinante en el desarrollo de la medicina a nivel académico, así como en la construcción de un sistema de Salud Pública organizado desde el Estado. Diversas revisiones historiográficas lo retratan como maestro en la escuela de medicina de la Universidad de Chile y como uno de los grandes agentes catalizadores en la unificación de los servicios de salud a nivel nacional. En lo político, se le ha tratado como uno de los representantes más visibles del Partido Conservador, en su rol de ministro, senador, embajador, y candidato a la presidencia. La intención de este trabajo es interrogar parte de su obra político-económica desplegada entre 1938 y 1946, a través de la revisión crítica de algunos de sus textos y discursos, referentes a un campo de discusión muy concurrido por diversos actores, desde distintas posiciones ideológicas en aquel período; problemas que dicen relación con la posibilidad de organizar un diseño del sistema social desde premisas biologicistas. Visto como un producto cultural (Kragh), los discursos médicos operan ejerciendo un poder que naturaliza un modelo de verdad sobre los procesos de salud y enfermedad (Foucault, Un diálogo; Berger y Luckman). Esto permite una reflexión acerca de las funciones ideológicas en contextos históricos determinados, viabilizando la investigación sobre las relaciones entre ideas científicas e intereses políticoeconómicos como conocimiento situado (Haraway, "Situated knowledge"). De esta manera, ideología y conocimiento funcionan como figuras complementarias, lo que posibilita la identificación de dispositivos que legitiman la desigualdad social desde lo institucional (Foucault, Historia 55).

La producción político-científica de Cruz-Coke Lassabe se vinculó a una tradición que lo llevó a desarrollar una variante de la medicina preventiva 
a nivel local, en una configuración que demandaba intervenciones específicas del Estado en materias de población; en otras palabras, que dotó de un sentido particular a las labores preventivas. Hasta el presente, se ha planteado que el trabajo académico y político de Eduardo Cruz-Coke se desarrolló desde su pertenencia al socialcristianismo y su militancia conservadora; los trabajos de Tomás Moulian, Isabel Torres Dujisin, Carlos Huneeus, María Paz Lanas, Pablo Toro y María Soledad Zárate dan cuenta de ello. Las páginas que siguen a continuación buscan generar una reflexión respecto de las relaciones existentes entre la propuesta liberal-conservadora de Eduardo Cruz-Coke -en su búsqueda por el desarrollo de una economía de carácter industrial- y el despliegue de un programa de medicina preventiva aplicado en la dirección de una economía dirigida. Al mismo tiempo, se pretende dar relevancia a sus consideraciones sobre el rol que desempeña la raza, en este proceso que él denomina como "conversión de la acción médica". La presencia de estas problemáticas se distingue en la creación de la Ley $\mathrm{N}^{\circ} 6.174$, que estableció el servicio de medicina preventiva en Chile y su continuidad en diversas alocuciones públicas, referentes al orden de necesidades para la concreción de un sistema de salud enfocado en lo económico, como una política de medicina del trabajo. Para ello, es importante abrir la discusión mediante una perspectiva biográfica sobre el personaje, abordando su trayectoria académica y profesional, y proyectar desde ahí su posterior producción política.

Eduardo Cruz-Coke nació en Valparaíso, estudió medicina en la Universidad de Chile entre 1915 y 1921, se graduó de médico-cirujano con una tesis titulada Tuberculosis y Vagotonismo, donde investigó las vinculaciones entre tuberculosis y afecciones del sistema nervioso. Durante su época de pregrado, el campo médico universitario chileno todavía se encontraba en proceso de formación, y recibió un gran influjo de las academias europeas mediante la contratación de docentes extranjeros y de profesionales chilenos educados en el viejo continente, con fin de actualizar las especialidades del gremio. En su proceso formativo destaca la influencia que tuvo del profesor polaco de Botánica Federico Johow, la de Adeodato García Valenzuela en la cátedra de Química Fisiológica y Patológica, y la del profesor italiano Juan Noé Cervani en la Cátedra de Zoología médica e Histología, de la cual Cruz-Coke llegó a ser ayudante en la unidad de trabajos prácticos del curso, gracias a un contacto cercano con el maestro de zoología -su relación afectiva y profesional, trascenderá en el tiempo hasta el fallecimiento de Noé en 1947- (R. Cruz-Coke). Como expone Marcelo Sánchez, Juan Noé arribó a Chile en 1912 desde Roma con el fin de completar el vacío que existía en la Cátedra de Zoología médica en la Universidad de Chile. Integró dentro del contenido del curso anatomía comparada, citología, 
histología, mendelismo y evolucionismo. En 1917 Noé añadió a este derrotero la teoría eugénica de Francis Galton y en una expresión temprana, el mendelismo fue la explicación genética de aquellas leyes de herencia biológica ("El profesor Juan Noé" 52).

La eugenesia, ciencia del "buen nacer", del "mejoramiento del linaje", instituida por Francis Galton Darwin en 1883 en su texto Inquiries into human faculty and its development, sistematizó un modelo científico racial, utilizando la antropometría para dar una lectura biológica al problema de la inferioridad, basada en la desigualdad de las razas humanas (Álvarez, Sir Francis Galton). Para principios del siglo XX, se había consolidado en gran parte del orbe una estructura científica sobre objetividad de estas premisas, que interpeló a la población desde la biología evolucionista, evitando la reproducción de factores morbosos, concentrando la represión de la reproducción en aquellos colectivos que encarnaban mayor riesgo para el Estado. La degeneración de las razas sirvió como filtro para juzgar problemáticas sociales propias del contexto urbano e industrial, lo que posibilitó la implementación de tecnologías para la selección artificial de la población y la eliminación de la vida sin valor, desde políticas públicas (Álvarez, "Eugenesia, ideología" 92; Palma, "Consideraciones historiográficas" 134). Así, durante las primeras décadas del siglo XX la eugenesia salió de las academias médicas e ingresó a los Estados, haciéndose parte del repertorio instrumental de organización demográfica, en busca de una normalidad social, establecida desde lo racial como conocimiento científico objetivo (Álvarez, "Eugenesia, ideología" 93).

Durante su primer año de estudios médicos, Eduardo Cruz-Coke formó parte de los miembros fundadores de la Asociación Nacional de Estudiantes Católicos (ANEC). Pablo Toro consigna este momento como definitorio tanto para su práctica socialcristiana privada, como en un elemento manifiesto de la tribuna conservadora (336). Desde 1917 formó parte del personal clínico en el Hospital San Juan de Dios, donde mantuvo una carrera continua, hasta convertirse en jefe del Servicio de Clínica médica del hospital en 1928. En 1921 también participó junto con Mamerto Cádiz en la creación del Instituto Médico Técnico Sanitas (R. Cruz-Coke). En 1925, a través de imprenta Chile, publicó su primera obra titulada La acidez iónica en clínica. Gracias a sus logros en la medicina clínica y a la difusión que tuvo esta investigación en el contexto médico chileno del período, pudo establecerse, entre 1925 y 1962, como profesor titular de Química fisiológica y patológica de la Escuela de Medicina de la Universidad de Chile, sucediendo a García Valenzuela tras su retiro (R. Cruz-Coke).

En 1925, el fisiólogo francés Louis Lapicque y el microbiólogo Eugène Wollman viajaron a Chile desde el Instituto Pasteur, donde visitaron los 
laboratorios de Química fisiológica y patológica de la Universidad de Chile. De esta manera, Eduardo Cruz-Coke pudo ampliar sus redes académicas en el viejo continente, lo que le permitió, entre 1926 y 1927, ir a formarse a Europa en laboratorios franceses, alemanes e ingleses, haciendo su entrada por el puerto de Barcelona, a través de su contacto con el fisiólogo catalán Jaume Pi-Sunyer i Bayo. Una vez en París, se integró a las investigaciones en desarrollo en el Laboratorio de Fisiología general de la Sorbona, sobre perfusión clorofórmica hepática en ratas con Louis Lapicque y al estudio de la fisicoquímica con Jean Baptiste Perrin y Louis Broglie. Transcurridos tres meses en París, Cruz-Coke se desplazó a Berlín, al laboratorio de Otto Heinrich Warburg y Hans Adolph Krebs ubicados en el Kaiser Wilhelm Institute, con fin de conocer sus descubrimientos recientes sobre metabolismo celular en tejido canceroso. Finalizada su estancia en Berlín, visitó al profesor de Bioquímica fisiológica Frederick Hopkins en su laboratorio de la Universidad de Cambridge, Inglaterra, en donde pudo estudiar, junto al descubridor de las vitaminas, el efecto que estas tenían en la contracción muscular, y a su regreso, junto con el profesor Carlos Monckeberg, fundó la Sociedad Biológica de Santiago en 1928, de la cual fue vicepresidente hasta 1939 (R. Cruz-Coke). Su rol en la escena médica chilena, le permitió, entre 1930 y 1931, organizar un segundo viaje a Europa, con fin de ampliar sus relaciones en el Instituto Pasteur, en el Hospital Necker para Niños Enfermos y en la Universidad de la Sorbona. Antes de finalizar esta segunda etapa de formación profesional, dedicó un tiempo especial para visitar el Instituto de Biotipología y Ortogenética de la Universidad de Génova, Italia, dirigido por el profesor Nicola Pende. (R. Cruz-Coke).

Dentro del debate respecto al concepto de eugenesia y sus posibles variantes, se ha definido a aquella que procura intervenir desde el ambiente como "positiva" y aquella que pretende la esterilización forzosa como "negativa" (Stepan). Este juicio de valor encubre las capacidades coercitivas de las intervenciones ambientales. Gustavo Vallejo y Marisa Miranda ("Iglesia católica y eugenesia latina") proponen que el impulso, de lo que ellos denominan "eugenesia latina", de marcado carácter ambiental, fue el resultado de la medicina desarrollada durante la Italia fascista. Esta variante supuestamente positiva conservó la disposición de intervenir a la población desde el marco racial, concentrándose en regular prácticas, conductas y espacios (Vallejo, "Las formas" 237). En este escenario, los trabajos de Nicola Pende (1880-1970) fueron determinantes en el desarrollo de esta eugenesia latina, cuyo objetivo fue detectar los riesgos latentes en el conjunto social, rastreando patologías o comportamientos no visibles, a través de lo que denominó biotipología y ortogenética. Nicola Pende fue un endocrinólogo italiano, quien obtuvo su título de médico en la universidad de Roma en 1903 
con una tesis acerca de las relaciones existentes entre la glándula suprarrenal y el sistema nervioso. Fue el primer rector de la Universidad Benito Mussolini en Bari y el fundador del Instituto Biotipológico-Ortogenético en la Universidad de Génova (Galera, "Hacia una fisiología" 365). Como lo formula Andrés Galera, para el siglo XX italiano, Nicola Pende protagonizó uno de los capítulos más relevantes por la biologización del comportamiento social, posicionado desde la endocrinología como disciplina, al relacionar la forma del cuerpo con sus funciones hormonales para explicar el origen de las anormalidades sociales (Galera, "Hacia una fisiología" 365-366). A través de uno de sus maestros, Achille de Giovanni, integró la Filosofía Zoológica de Jean-Baptiste Lamarck (1809), quien la utilizó para explicar la morfología del cuerpo en relación a su medio de conformación; donde la necesidad y la función crean el órgano (Galera, "Hacia una fisiología" 367).

Como aclaran Galera, Miranda y Vallejo, la biotipología de Pende estuvo atravesada por un tipo de individualidad constitucionalista, que trazó diferencias con las propuestas anatómicas y fisiológicas de aquel momento, que pretendían una homogeneidad somática en la figura abstracta de especie (Galera, "Hacia una fisiología" 369). Pende hizo responsable al sistema endocrino de las conductas anormales, uniendo lo hormonal, lo fisiológico y lo moral. Profundizó esta deriva, planteando que ya no eran suficientes las señales externas para identificar población considerada como riesgosa; así pudo construir un punto de observación de lo no aparente, a través de la creación de un sistema de análisis preventivo pensado para ser aplicado sobre la población sana, mediante la instauración en Italia de una serie de institutos biotipológicos, con fin de desarrollar una profilaxis de las debilidades morales (Galera, "Hacia una fisiología" 370; Galera, "La escuela"; Vallejo y Miranda, "Los saberes del poder" 432-433).

Si la biotipología estaba a cargo de identificar a la población riesgosa, mediante un levante estadístico de patologías en base a la aplicación de fichas biotipológicas en supuestos sanos y anormales sociales, la ortogenética, otra arista de la propuesta de Pende, tuvo la labor de resguardar el crecimiento psicofísico de la población, buscando anticiparse a los efectos que pudiera ocasionar el ambiente, interviniendo sobre el medio con fin de mejorar la raza, en una labor preventiva (Galera, "Hacia una fisiología" 373-374). Este programa se extendía en tres frentes, la educación, la investigación, y la planificación científica de la población, haciendo parte del proceso a la eugenesia como tecnología de control, diseñando la intervención desde la vigilancia, de la niñez a la adultez, corrigiendo las circunstancias ambientales que permitían la corrupción individual, en vez de desplegar políticas desde la esterilización forzosa (Galera, "Hacia una fisiología" 374-375). Una de las características principales de esta propuesta fue el paso de una 
higiene orientada desde lo colectivo a otra basada en el análisis individualizado, apuntalado por un diagnóstico minucioso obtenido de la pesquisa individual. Este tránsito tuvo como objetivo analizar las predisposiciones mórbidas de la población sana a través del examen médico preventivo, lo que dotó al Estado de una mayor gobernabilidad, a través de la detección temprana de anormalidades ocultas en espacios habitados por supuestos sanos, con fin de anticiparse a sus efectos (Vallejo, "Las formas" 240).

Para el caso de Eduardo Cruz-Coke, es posible rastrear ciertas correlaciones entre este acercamiento hacia la figura de Pende y la biotipología, en su forma de identificar el riesgo y de plantear mecanismos para examinar población sana en busca de anormalidades no deseadas, posibilitando lo que denominó como "conversión de la acción médica", hacia una medicina preventiva y dirigida. Su carrera política se inició en 1937; por recomendación de uno de sus más cercanos compañeros de clase, Hernán Alessandri, destacado médico e hijo del presidente de la República, llegó a ejercer como ministro de Salubridad, Asistencia y Previsión hasta septiembre de 1938 durante el segundo período presidencial de Arturo Alessandri Palma. En esta labor ministerial, Cruz-Coke ha sido designado como una pieza central en el desarrollo de un modelo de Estado de Bienestar dentro del contexto chileno de principios del siglo $\mathrm{XX}$, donde se le otorgó un lugar preponderante también al pensamiento socialcristiano como agente garante de los derechos sociales (Huneeus y Lanas; Toro 345). Sin embargo, hasta el momento no se ha tensionado el proceso de reproducción del sistema de clases mediante la intervención biológica de lo social, planteándose el fenómeno como una integración pacífica de la clase trabajadora al sistema político y económico (R. Cruz-Coke; Huneeus y Lanas).

El debate por la Salud Pública en Chile se volvió manifiesto en distintas agrupaciones médicas, capitalinas y regionales, y hubo muchos personajes importantes de la escena médico-política chilena abocados en sus distintas aristas. Una de aquellas fue la preocupación por la alimentación popular a lo largo de la primera mitad del siglo XX (Yáñez, "Gobernar es alimentar"). Gracias a su activa participación en esta área, recalcando las aproximaciones científicas a este problema y los efectos que genera en el estado biológico de la población, se ha levantado la figura de Eduardo Cruz-Coke, en su labor ministerial, como un baluarte de la salud pública chilena. Esta temática, que abordó desde finales de la década de 1920, como factor ambiental de alto impacto en el desarrollo de las constituciones individuales de la clase trabajadora chilena, lo impulsó a desarrollar diversas iniciativas, como la fundación de la Revista chilena de medicina y alimentación en 1933 (R. Cruz-Coke). El problema de la alimentación popular durante la década de 1930, también se abordó desde sectores simpatizantes de las 
ideas eugénicas a nivel médico (Sánchez, “Alimentación y eugenesia”; Sánchez y Cárcamo), así lo sugiere la circular general del Primer Congreso Nacional de Alimentación Popular, organizado por la Sociedad Médica de Valparaíso en septiembre de 1930, consignándose la mala alimentación como un "innegable desmedro del presupuesto familiar y de la robustez de nuestra raza" (Comisión organizadora). Algunas personalidades de aquella sociedad, patrocinadora de este evento, fueron Vicente Dagnino, Gustavo Fricke, Víctor Grossi de la Guarda, Hans Betzhold Hess y Carlos Schwarzenberg. Esto da cuenta tanto de acuerdos profesionales, como en la circulación de conocimiento eugénico sobre el riesgo que implicaba la debilidad fisiológica para cumplir una meta desarrollista. Un año después, se promulgó la Ley N. ${ }^{\circ} 6.236$ de alimentación de madre e hijo y en el 31 de enero de 1938, tras siete meses de discusión parlamentaria, se promulgó la Ley N. ${ }^{\circ} 6.174$ que estableció el servicio de Medicina preventiva, como una continuación de la política de seguros que ya se estaba desarrollando en el país, a través de la Ley N. ${ }^{\circ} 4.054$ de Seguro obligatorio para los trabajadores por enfermedad, invalidez, vejez y muerte, que creó la Caja de Seguro Obligatorio, impulsada por el Dr. Exequiel Gonzáles Cortés. En una campaña de moralización continua, aquellas medidas tuvieron gran compromiso político y propagandístico como divulgación sanitaria en las principales ciudades chilenas, con fin de modificar los hábitos sobre cuidado de la infancia, alimentación y prevención de enfermedades de trascendencia social; políticas desplegadas por Cruz-Coke que vieron continuidad en la gestión posterior del Frente Popular (R. Cruz-Coke, R; Huneeus y Lanas).

En el año 1941, Eduardo Cruz-Coke inició nuevamente una carrera política, esta vez como uno de los abanderados más seductores del partido conservador en la elección parlamentaria por el distrito de Santiago, siendo reelecto en 1949 hasta 1957. Durante su largo ejercicio, generó importantes nexos políticos, dentro de los cuales destaca la figura de Salvador Allende y con su discípulo, otrora ministro de Salubridad, Jorge Mardones Restat, entre 1950 y 1952, durante el gobierno de Gabriel González Videla. Gracias a esos vínculos, pudo establecer canales de gestión para profundizar sus avances en materias de alimentación, como para la unificación de los servicios de salud a nivel nacional. En 1942 publicó desde el Laboratorio de Química fisiológica y patológica de la Universidad de Chile, su obra endocrina más relevante, La Corteza Supra-renal, uno de los primeros compendios a nivel internacional escritos sobre las funciones de esta glándula, abordando su morfología, química, fisiología y patología.

Dada la popularidad que alcanzó como político, el Partido Conservador lo levantó como candidato para la campaña presidencial de 1946 tras la muerte del presidente Juan Antonio Ríos. Dentro de sus elementos de propaganda aparecía 
la apelación a la ciencia como juicio superior frente a la argumentación política tradicional, haciendo uso de esta categoría como plataforma para solucionar la problemática de la cuestión social, siendo representado como un "médico que sería capaz de sanar las dolencias sociales del país" (Toro 346). A pesar de no conseguir la banda presidencial y quedar como segundo candidato con mayor cantidad de votos, tanto a nivel político como académico, la influencia de CruzCoke tuvo un lugar preponderante para Chile como en el extranjero, siendo laureado como Doctor Honoris Causa en la Universidad de París, nombrado Caballero de la Legión de Honor en Francia, en España fue hecho miembro de la Academia de Medicina de Barcelona, fue declarado miembro vitalicio de la Academia de Ciencias de Nueva York y miembro honorario de la Asociación de Cirujanos de Estados Unidos. En Inglaterra fue electo vicepresidente del primer Congreso Internacional de Bioquímica en Cambridge en 1949. En América Latina fue miembro de las Academias de Medicina de Buenos Aires, Montevideo, Lima y México (R. Cruz-Coke).

Toro, Zárate y Moulian plantearon en distintos momentos que Eduardo Cruz-Coke se mantuvo distanciado del funcionalismo económico y de la tecnocracia, identificando al nacionalismo como un factor ausente en el desarrollo de su política pública, únicamente utilizado como estrategia de naturaleza integradora. Asimismo, su accionar habría sido determinado por un impulso democrático-liberal y principios de orden moral-religioso (Toro 346). Sería interesante entonces ver qué tan alejado permanecía de aquellas posiciones y poner atención en el modo que tuvo de pensar y hacer política pública, integrando estos parámetros conformados desde el determinismo positivista en la discusión. Como ministro de salubridad, se le presentó la oportunidad de poner en marcha un sistema médico de carácter preventivo y dirigido específicamente a la clase trabajadora de aquel contexto, con el fin, no solo de solucionar problemas inherentes a la cuestión social en el período, sino de corregir también el comportamiento obrero frente al trabajo y sus efectos económicos. Al mismo tiempo, este sistema le permitía revelar una morbilidad oculta en la población activa, haciendo más eficiente el uso de este contingente considerado como recurso, que representaba tanto un riesgo como un potencial. Para esto, integró preceptos biotipológicos, devengándose un programa de salud pública enfocado en lo individual, que priorizaba la búsqueda del mal oculto en el supuesto sano, como un levante estadístico de peligros latentes para el Estado y la economía, evitando los efectos que tiene la predisposición orgánica de la clase trabajadora en la propagación de enfermedades sociales. Los instrumentos que utilizó para la identificación de morbilidad oculta contemplaron el desarrollo de fichas biotipológicas, aplicables a los sujetos que se sometiesen al examen médico 
preventivo instaurado por la Ley N. ${ }^{\circ}$ 6.174. En su perspectiva, la calidad de la población estaba determinada por factores hereditarios y ambientales; lo que proyectó en la mejor reproducción de la fuerza de trabajo mediante el cuidado de estos componentes, desarrollándolos a través de una reforma en la política de seguros sociales.

\section{PREVENIR Y DIRIGIR: OBJETO Y SENTIDO DE LA OBRA MINISTERIAL DE EDUARDO CRUZ-COKE}

Al cuestionar la reproducción de discursos médicos respecto al problema de la población a nivel global, uno de los temas que ha adquirido preponderancia en las últimas décadas es el análisis sobre los mecanismos mediante los cuales se han generado sistemas de administración pública de la salud. Para desplegar estos mecanismos de control biológico como faceta del poder hegemónico del Estado, se requirió en distintos momentos y territorios, de argumentos que legitimasen las intervenciones en esta materia, apelando a la necesidad de mayor rendimiento económico. El rendimiento en este sentido debía ser traducido en una población que representase menor riesgo; para el caso chileno en ese contexto, enmarcado en un anhelado proceso industrializador, implicaba que esa población trabajadora no enfermase, para resguardar la producción y consumo de bienes. Lo interesante de esta perspectiva es que permite introducir formas más sutiles de penetración biopolítica; Eduardo Cruz-Coke Lassabe fue uno de los personajes clave en este proceso de colonización científica del cuerpo social desde el Estado para asegurar un campo de acción a la economía liberal. A lo largo de sus textos y discursos políticos, Cruz-Coke describió una serie de formas conductuales que representaron una necesidad en términos económicos y morales para brindarle operatividad a la base legal de aquel sistema de carácter preventivo. El recorrido anterior permite no solo identificarlo dentro de la política de partidos, sino también imbricar aquel posicionamiento con escuelas de pensamiento científico que disponen un actuar particular. A razón de estas premisas y a la luz de las múltiples biografías que recogen su trayectoria, se plantea esta lectura sobre la "conversión de la acción médica". La naturalización de aquellas conductas requeridas frente a los procesos de salud/enfermedad explicita un sentido en aquella disposición, el detalle se encuentra en la sutileza para transitar hacia la pesquisa de supuestos sanos; más bien, sobre las formas con las cuales se emprende la búsqueda. Es necesario hacer un desglose de sus argumentaciones políticas referentes a esta problemática y situar la presencia de factores raciales al momento de plantear las funciones que tendría la organización 
de un sistema de salud, en correlación con el riesgo económico. Veremos a lo largo de los siguientes apartados de qué manera, y en relación a qué fenómenos económicos se hace referencia a estas características raciales.

Como ministro de Salubridad gestionó la Ley No. 6.174 que estableció el Servicio de Medicina preventiva, proyecto que adquirió enorme significado tanto en el momento como en relecturas. Posterior a la aplicación de la ley, ese mismo año, a través de Editorial Nascimiento, publicó un libro titulado Medicina preventiva-Medicina dirigida (1938), que contuvo "los fundamentos biosociales y económicos de la Ley de Medicina Preventiva"; una detallada explicación de los sentidos que esta tenía, como preventiva de las enfermedades de trascendencia social y dirigida específicamente a la clase trabajadora. Estos fundamentos se hicieron operativos a través de un modelo de identificación de morbilidad oculta significante para la economía nacional, integrando en ella "las legislaciones anteriores sobre seguros sociales" (E. Cruz-Coke, Medicina preventiva 5). A través del análisis estadístico de la situación médico-social nacional -análisis compartido en cuanto a cifras de natalidad, mortalidad y morbilidad con otras lecturas del mismo fenómeno llevadas a cabo en el período- la propuesta de 1938 consideraba en gran medida las influencias directas que tenía la salud de la clase trabajadora sobre la economía, puntualizando un objetivo particular que marcó diferencias con otras lecturas; focalizándose "a la acción de la salubridad sobre el consumo" (E. Cruz-Coke, Medicina preventiva 6). Este factor se convirtió en un rasgo axiomático, donde la producción estaba subordinada ante el consumo, como motor de la economía y de las funciones de seguridad social.

Una de sus aportaciones en este texto fue la distinción entre "economía financiera", que beneficiaba el cálculo del costo monetario de la población para el Estado, y "economía humana", que enfocaba sus esfuerzos en el control de los elementos productores y consumidores de riqueza. Desde esta perspectiva, para Cruz-Coke "la salud es quizás el más importante factor que gobierna la economía humana en su aspecto de ciencia experimental y de disciplina concreta". Para el ministro, los problemas sanitarios devengados de la cuestión social eran reflejo de la "inadaptación del individuo al medio en que se desarrolla" (E. Cruz-Coke, Medicina preventiva 9). Propuso esta relación de la siguiente manera, "la insuficiencia económica individual se traduce siempre en una morbilidad creciente", lo que sirvió para explicar la expansión de enfermedades de trascendencia social como dependientes del salario. Esta predisposición representaba un círculo vicioso, donde la enfermedad era causa de las malas condiciones de vida, y afectaba en las capacidades de los trabajadores para conseguir ingresos suficientes que permitiera una mínima capacidad de capitalización. Dentro de este texto, Cruz-Coke expuso que aquel 
factor, "llevaría a irremediables deficiencias tanto en la capacidad de producción como de consumo", por lo que se le hizo inminente establecer "compensaciones naturales y medidas de gobierno que amortiguaran los efectos anotados" (E. Cruz-Coke, Medicina preventiva 10). Con el fin de disminuir los riesgos de morbilidad y mortalidad para la economía, como un resguardo de la capacidad de producción y consumo desde una plataforma biológica, planteó la urgencia de generar medidas de contrapeso para afianzar la supuesta regulación natural del mercado. Respecto de las alzas de salarios, para él, una "medida simplista", propuso que:

[El alza de salario] adolece como todas las soluciones directas del defecto de no ir al fondo del problema y de no indicar de qué manera esta alza será posible, ya que no podemos olvidar que no se puede pagar a un individuo más de lo que produce y que el valor de lo que produce no depende sólo de nosotros, sino que, también, de valores y condiciones internacionales (E. Cruz-Coke, Medicina preventiva 10).

Si la socialización de los recursos operaba antagónicamente sobre la socialización del riesgo económico ¿cómo obtendría la clase trabajadora el nivel de ingresos adecuado a las expectativas del ministro sin recurrir a la reforma salarial? Uno de los frentes que propuso intervenir fue el exceso de reposo de la clase obrera durante estados de enfermedad, que significaba para él un problema biológico endémico nacional y su superación era un fin en sí mismo de la Ley. En su perspectiva, el trabajador chileno "compra reposo envés de cosas. Las consecuencias de este hecho son graves para la economía del país y plantea el problema de la pasividad transitoria que la Ley de Medicina Preventiva contribuye a corregir" (E. Cruz-Coke, Medicina preventiva 10). Aquella conjetura se sustentó en base al reconocimiento del "supuesto sano en el cual se encuentra un porcentaje de morbilidad latente". Este examen, hecho a partir de la identificación progresiva de "morbilidad latente" y realizado en los servicios del Seguro Obrero Obligatorio, dio sentido a la ley con fin de "impedir que el individuo reaccione con reposo cada vez que pueda", ya que, desde un estándar fisiológico, lo esperado es que el trabajo constituyese "no solo una tendencia natural sino, también, el medio de pagarse la satisfacción de sus aspiraciones próximas organizadas en una perspectiva de posibilidades sucesivas" (E. CruzCoke, Medicina preventiva 13). Así, encuadró uno de los sentidos de la ley como una "política del trabajo que actúa sobre el consumo", la cual era necesario sustentar en la "capacidad orgánica y por una organización social de los deseos, tarea que corresponde a una previsión social de tipo biológico" (E. Cruz-Coke, 
Medicina preventiva 13). Para esta iniciativa preventiva, que contemplaba una organización social de los deseos respecto a una política del trabajo que actuaba sobre el consumo, la educación primaria fue vista a modo de herramienta de higiene mental, sirviendo como espacio de protección de la infancia en "vista de una acción posible sobre su medio y de una reacción de este sobre su capacidad" (E. Cruz-Coke, Medicina preventiva 13); orientada para sincronizar higiene y ahorro "sobre las bases de una organización de los reflejos desde los más inconscientes hasta los más condicionados" (E. Cruz-Coke, Medicina preventiva 13). Estas disposiciones sobre el trabajo, el reposo y la primera infancia, fueron vistas como garantes de una economía de consumo, que en su transcurso relacionaron la determinación de los deseos con "la integridad de las funciones orgánicas." (E. Cruz-Coke, Medicina preventiva 13). Para Eduardo Cruz-Coke, la organización de este proceso implicaba:

la orientación de una política de salubridad sobre las bases económicas señaladas, tomando en cuenta en primer lugar nuestro hombre chileno. Y si nos hemos referido principalmente a su significado en el consumo, es porque creemos que es lo que en un país como el nuestro hay que estimular primero y porque es el consumo aquello sobre que más propiamente puede actuar la política de salubridad que señalamos. (E. Cruz-Coke, Medicina preventiva 13).

El consumo tuvo un valor preponderante como eje en su lectura de la realidad médico social, en su definición de los valores nacionales y su forma preventiva de hacer salud pública; para Eduardo Cruz-Coke "la importancia de un pueblo no depende de lo que es capaz de producir, sino de lo que es capaz de consumir. La factoría produce, la nación consume" (E. Cruz-Coke, Medicina preventiva 13). De esta manera, ponderó las patologías que debían incluirse en una pesquisa preventiva según una escala de interés sobre sus efectos en el trabajo. Dentro de este grupo de enfermedades se encontraba "la tuberculosis, la sífilis, el reumatismo, las enfermedades del corazón y de los riñones; como también las enfermedades derivadas del trabajo: el saturnismo, la antracosis, la silicosis, la anquilostomiasis y otras de la misma índole" (Ley No. 6.174). Sobre la importancia que tenían estas enfermedades, estableció un método de intervención "sobre las bases técnicas del saneamiento, de la epidemiología y de la pesquisa oportuna de la afección precoz en el supuesto sano", con el fin de disminuir los efectos económicos del absentismo laboral y así "organizar al hombre consumidor, estructurado por aspiraciones y deseos" (E. Cruz-Coke, Medicina preventiva 14). Para el ministro, esta implementación requería de 
un proceso de readecuación social. Así, uno de los sentidos de su proyecto, plasmados en esta obra, estuvo puesto en la convicción de que "la máquina que hay que reparar en nuestro país, con más urgencia que otras es el hombre, pero no cualquier hombre, sino nuestro trabajador", encausando el cuidado del cuerpo de la clase trabajadora, como resguardo del "principal elemento positivo de riqueza de que podamos disponer" (E. Cruz-Coke, Medicina preventiva 14).

Dentro de su manifiesto explicó que el examen de supuestos sanos le permitió establecer la distinción entre "morbilidad estadística" y "morbilidad real" (E. Cruz-Coke, Medicina preventiva 14), donde esta última sobrepasaba a la primera "hasta el punto de que en ciertas fábricas un 30\% de los obreros han debido ser enviados a los dispensarios de la caja de seguro obligatorio" (E. Cruz-Coke, Medicina preventiva 16). Desde un rol activo en la identificación, planteó que "esperar a los enfermos en los dispensarios era errar el camino", que, mediante un sistema basado en la espera, la efectividad económica de la intervención médica de enfermedades como la sífilis o la tuberculosis, llegaba sólo a un cuarto del total de enfermos, "quedando sometido el resto a una inútil y costosa prolongación de su vida" (E. Cruz-Coke, Medicina preventiva 17). Para el ministro, esta condición atentaba directamente contra los regímenes pretendidos de producción nacional. El reconocimiento temprano mediante el análisis preventivo de enfermedades que eran adquiridas en los ambientes laborales, o que interferían en los procesos de producción, fue uno de sus focos de acción, y lo dispuso de la siguiente manera:

Estos fundamentos están en relación con un concepto del trabajo basado a la vez en la fisiología individual y en la biología social, con un concepto de la economía de la previsión aplicada allí donde puede operar con más eficacia sobre la compra de probabilidades de vida y con una acción médica establecida, según normas precisas, de manera que constituye una verdadera medicina dirigida (E. CruzCoke, Medicina preventiva 29).

Esa dirección que buscó imprimir, estuvo dedicada a que el Estado obtuviera ganancia en riquezas y productividad a través de la mejora constitucional individual de la clase trabajadora (E. Cruz-Coke, Medicina preventiva 30). Dentro de este texto que operaba como una explicación acerca de los fundamentos de la Ley de medicina preventiva, la posibilidad de descanso fue contemplada solo como una finalidad del trabajo; elemento que para Cruz-Coke "está en desacuerdo con la fisiología y la sicología del hombre normal. La función del trabajo es inherente a la naturaleza humana". Le fue necesario entonces enmarcar 
dentro de su discurso al trabajo como algo natural y deseable. Así, a través del aprovechamiento total de la capacidad productiva de los sostenedores, mantener a las familias completas. Algo por lo que destaca en revisiones anteriores, es por su distinción entre "previsión financiera" y "previsión biológica", donde la última procede según los parámetros de la economía humana; desde su perspectiva significaba "reparar a tiempo el hombre-máquina para prolongar su vida útil y ponerlo en condiciones de adaptar su trabajo a su capacidad" (E. Cruz-Coke, Medicina preventiva 33). La Ley de Medicina preventiva apuntaba a aminorar el porcentaje de pasivos "por medio de la represión biológica de la invalidez" (E. Cruz-Coke, Medicina preventiva 38), buscando adelantarse a las circunstancias que hicieran al obrero dejar su trabajo, resguardando la economía individual y nacional, mediante la identificación temprana de patologías:

impedir que la enfermedad se desarrolle, que la invalidez y la vejez se presenten prematuramente, para que así la muerte aparezca al fin como una consecuencia lógica y a su hora. La previsión financiera debe operar sobre aquello que desborda la previsión biológica, o sea, sobre el mal inevitable, así como vimos, ya que la previsión biológica individual realizada por medio de la medicina preventiva individual tal como la hemos establecido, desborda la de la Profilaxia y del saneamiento (E. Cruz-Coke, Medicina preventiva 38).

La propuesta de medicina preventiva estuvo orientada desde los efectos del azar biológico en el consumo; sus modificaciones buscaron adaptar a la población a los ritmos del sistema industrial, con miras a una economía manufacturera en reemplazo del modelo primario exportador, sin modificar las condiciones de la clase trabajadora, actuando anticipadamente sobre las consecuencias de las enfermedades de trascendencia social. Cobra sentido que esta reforma se plantee como un desborde a la lógica profiláctica, puesto que cambia el orden de los factores en el análisis del riesgo biológico. Para el ministro, esta redirección de los sentidos de la salud pública implicó para Chile, "inaugurar una nueva política de previsión sociobiológica, como la que este país necesita." (E. Cruz-Coke, Medicina preventiva 42). La acción de la medicina dirigida era únicamente desplegable a través de la participación de médicos como expertos, ya que su capacidad innovadora estaba "en la exactitud del examen de salud" (E. Cruz-Coke, Medicina preventiva 45), que permitía brindar una justificación científica del reposo. Este proceso definido en su texto como "conversión de la acción médica", no representó mayores cambios institucionales, sino la coordinación de los servicios de salud existentes, orientando su acción "de preferencia hacia los estados iniciales y no a los finales 
de las enfermedades, por medio de la investigación sistemática de esos estados" (E. Cruz-Coke, Medicina preventiva 47). La acción propuesta permitía resguardar los capitales necesarios para la producción, al mismo tiempo que se disminuían los conflictos que significaba perder capacidad industrial, lo que posiciona a CruzCoke y su política en una función directa con la economía. La Ley No. 6.174 fue una de las salidas técnicas que se plantearon en el período al problema de la cuestión social, que actuó poniéndole un valor al cuerpo del trabajador en una dinámica de consumo y no tan solo productiva, rasgo diferenciador con sus pares en este campo. Al tiempo que reivindicaba una mayor población sana que aumentara el rendimiento económico, esta propuesta invertía las relaciones entre pobreza y enfermedad, haciendo de los estados patológicos una causa de la pobreza; como un importante factor que ampara el avance de las patologías en el cuerpo social, en un momento donde la presencia de enfermedades infecciosas estaban arraigadas en los sectores populares. Esto contribuyó a invisibilizar la etiología social de la enfermedad, entendida como "aquélla cuya causa tiene su origen en la propia organización de la comunidad y, más concretamente, puesto que así se desprende de su gestación histórica, en la desigualdad social" (Rodríguez Ocaña 341).

La acción de reconocimiento en el supuesto sano no requirió de alarde, sino más bien de la naturalización del fenómeno, "se irá a buscar a la fábrica al obrero que no concurra espontáneamente a la policlínica; en el campo se le esperará en el dispensario, cuando busque al médico para su afección banal" (E. Cruz-Coke, Medicina preventiva 48). Por medio de la ley, esto se hizo extensivo a través de la institucionalidad existente, integrando el reconocimiento de manera metodológica; la reorientación del sistema implicó convertir a los servicios de salud primarios en los recolectores de información sobre el riesgo biológico y desde ahí disponer el control de los factores ambientales para la mejora constitucional de la fuerza de trabajo; el paciente, "se verá acogido para un examen de salud simple en vista de las afecciones fundamentales citadas", haciendo de la identificación algo imperceptible, "lo que más interesa a la salud no es justamente la enfermedad de que viene a quejarse el sujeto, sino aquella que, en un plan de medicina dirigida el médico le descubre" (E. Cruz-Coke, Medicina preventiva 49), reforzando la supremacía de la técnica médica sobre la autogestión del cuerpo.

En tanto enfermedad social, dentro de este manifiesto, Cruz-Coke reconoció la tuberculosis como una patología multifactorial con dos elementos, "uno infeccioso y otro económico-social". El componente económico, desde su lugar de enunciación, surgía como consecuencia de la inadaptación de los individuos a los regímenes de habitabilidad urbana y de trabajo industrial moderno, e incidía "en el terreno orgánico en el cual se desarrolla la afección". 
Factores como el hacinamiento, la mala alimentación y el exceso de trabajo, consecuencia de un "aprovechamiento inadecuado de los medios por falta de cultura", posibilitaba la manutención de un circuito donde "la infección progresa en un terreno apto para su desarrollo y adquiere un carácter epidémico" (E. Cruz-Coke, Medicina preventiva 55). La falta de cultura higiénica como característica de clase, elemento con el cual desculpabiliza al modelo económico de sus efectos en la población, la relacionó programáticamente con el rol de las escuelas y la organización social de los deseos propuesta dentro de la ley. De esta manera, estipuló que los fundamentos para la lucha antituberculosa "refieren en orden de importancia al salario y a una educación que permita aprovecharlo, por una parte; al alimento y a la habitación, por otra" (E. Cruz-Coke, Medicina preventiva 56). Lo que se vislumbra es que pretendía generar un reacondicionamiento de la clase obrera, sobre un nuevo orden de necesidades. La ley pretendía desarrollar "una acción indirecta sobre la enfermedad, acción destinada a eliminar de ella el componente económicosocial" (E. Cruz-Coke, Medicina preventiva 56). Asimismo, buscó darle una aplicabilidad masiva al instrumento -la modificación de la política de seguros sociales planteaba una vía sólida de implementación- sobre un universo que contemplaba "prácticamente la totalidad de los activos del país; precisamente aquellos que el Estado tiene interés de curar y recuperar primero" (E. CruzCoke, Medicina preventiva 58). Su propuesta de medicina preventiva y dirigida fue planteada en este itinerario como un programa de medicina del trabajo. En su desenvolvimiento, un factor relevante fue que, mediante esta tribuna, se le pudo conceder al obrero "su salario íntegro durante todo el tiempo que requiera su mejoría" (E. Cruz-Coke, Medicina preventiva 58). La posibilidad de salario íntegro estuvo dirigida a la merma que significa el cese de la producción, a razón de la pasividad transitoria y la compra de reposo para la circulación de capital, dirigida a sostener la capacidad adquisitiva de la clase trabajadora, durante el transcurso del descanso producto de estados patológicos.

La sífilis se integró a este programa preventivo como "una enfermedad hereditaria y contagiosa", ponderó sus efectos en orden de importancia, sobre su influencia en la capacidad de trabajo, como productora de daño cardiovascular y nervioso. Su acción sobre este grupo de enfermedades la amparó en la necesidad del Estado de resguardar la estabilidad económica, ya que ambas enfermedades contribuían a "disminuir la resistencia individual en todo sentido y en servir de elemento de desorganización social" (E. Cruz-Coke, Medicina preventiva 60). Si bien fue una preocupación de carácter general en el campo médico previo al descubrimiento de la penicilina, el problema de la sífilis brindó un giro en relación con el diseño de una política de prevención de las enfermedades de 
trascendencia social. Hacia el final de su explicación sobre los fundamentos de la ley, describió su significado en la gestión administrativa:

Con relación a la salubridad, bajo este último punto de vista, dos objetivos se nos presentan como lo más urgente de alcanzar para mejorar las condiciones físicas y morales de nuestra raza: Neosalvarsán para todos los que lo necesiten y leche suficiente para las madres y sus hijos en lactancia o primera edad. Todo lo que se gaste en estos elementos representa beneficio nacional efectivo (E. Cruz-Coke, Medicina preventiva 61).

La lucha antisifilítica a través de preparados mercuriales y la alimentación infantil, tuvieron un lugar especial dentro de la Ley No. 6.174 como propósitos del fortalecimiento físico y moral de la raza chilena. Sobre la producción de leche, propuso como requerimiento "una política pública agrícola y económica dirigida por el Estado para obtener, poco a poco, lo que señalamos en tantas ocasiones como las normas de la alimentación de la raza misma." (E. Cruz-Coke, Medicina preventiva 61). Estos primeros atisbos abren una ventana interpretativa, sobre la presencia de la raza como parte de los factores en el desarrollo de una política como la anteriormente descrita, algo que siguió haciéndose presente en su producción posterior. La dirección con la que se interpeló a la población respecto de la económica no solo estaba puesta en la clase trabajadora, sino en que esa clase trabajadora pertenecía a un segmento particular de la raza nacional, con componentes desmejorados, susceptibles de ser regenerados o vigorizados mediante la intervención de factores ambientales. Cruz-Coke compartió el diagnóstico hecho desde la lectura racial con la escena médica del período, pero no el sentido con que deben ser puestos los esfuerzos para mejorar aquellas características, en ese contingente atravesado por variables de carácter racial. La variación respecto a la escena médica chilena, que debatía sobre estas temáticas, está en el tipo de solución técnica propuesta, la consigna no estaba puesta en segregar a los obreros que tenían o no derecho a reproducirse, sino que, en una gran masa de población obrera, aquellos trabajasen más horas, capitalizaran más y que así alimentasen de mejor manera a sus familias, sin cambiar su rol histórico de clase. Una de las proposiciones que le permitió generar acuerdo político entre los partidos de izquierda, centro y derecha, respecto a la necesidad de implementar estas modificaciones fue "comprar salud barata a tiempo, que es comprar salud barata, para comprar mucha salud, toda la salud que el pueblo necesita." (E. Coke, Medicina preventiva 62). Años más tarde en el Senado, esta premisa volvió a cobrar importancia sobre el establecimiento de una política alimenticia y de protección a la infancia como defensa de la raza. 


\section{FUNDAMENTOS POLÍTICO-ECONÓMICOS EN UNA PERSPECTIVA GLOBAL}

La Ley de Medicina Preventiva - que contenía dentro de sí la operatividad de aquellos fundamentos, descritos a partir de su manifiesto, en el apartado anterior- tuvo un carácter extensivo a la población económicamente activa del país en aquel contexto. Sería interesante entonces, revisar las descripciones que Eduardo Cruz-Coke Lassabe hizo acerca del marco económico donde inscribió a ese segmento de la población, y desde el cual la proyectó en un horizonte de posibilidades.

Durante 1946, Editorial Nascimiento publicó Discursos: políticaeconomía-salubridad-habitación-relaciones exteriores-agricultura; un volumen compilatorio de alocuciones públicas pronunciadas por Eduardo Cruz-Coke, el cual contenía trece apartados con intervenciones nacionales e internacionales, realizadas durante su primer período senatorial, entre 1941 y $1946 .{ }^{1}$ Los editores justificaron la compilación con el fin de "contribuir así, modestamente, a la formación de nuestra conciencia cívica" (E. Cruz-Coke, "Prólogo" 3-4). El libro alcanzó a recoger un discurso enmarcado dentro de su campaña presidencial pronunciado el 5 de mayo de 1946, mismo mes de redacción del prólogo del volumen, donde desplegó los pilares fundamentales de un futuro programa de gobierno. La publicación de este volumen fue un artefacto de campaña de rápida gestión -la elección presidencial de 1946 se llevó a cabo el 4 de septiembre- el libro en sí mismo fue una acción política para posicionar a Eduardo Cruz-Coke en una trayectoria continua y objetiva de producción de conocimiento políticocientífico.

El 15 de septiembre de 1941, pronunció en el senado un discurso sobre la "creación de capitales nacionales" (E. Cruz-Coke, "Creación de capitales" 17). En su cuenta acerca de los factores necesarios para la generación de riqueza, planteó que las reformas salariales, ya sean del sector público o privado, no tenían sentido si no venían acompañadas de "una política económica que aumente la producción de manera que con mayor dinero podamos comprar más y no menos cosas" (E. Cruz-Coke, "Creación de capitales" 19). Con un sentido civilizatorio, considerando las adaptaciones de la población urbana que requería para el desarrollo de su proyecto de industrialización nacional, propuso que "no es el caso ofrecerle al pueblo una vuelta a la ruca"; como nación, "hemos de colocarnos

1 Todos los discursos que se analizarán de aquí en adelante están contenidos en este volumen editado en 1946, sin embargo, la citación se hará de acuerdo al nombre propio de cada discurso con el fin de desplegar mayores interrelaciones analíticas entre ellos. 
dentro del imperativo de tener que crear las riquezas de las cuales queremos gozar" (E. Cruz-Coke, "Creación de capitales" 21). Este posicionamiento fue tanto político como económico, al plantear, sobre las exigencias de los partidos de oposición y sectores populares a nivel nacional, que "nuestras protestas contra el imperialismo no son otra cosa que vagas lamentaciones de mendigos"; reivindicaciones "de las cuales jamás nos haremos cargo los chilenos que creemos en las virtudes viriles de nuestra raza" (E. Cruz-Coke, "Creación de capitales" 21). En un contexto de importantes desplazamientos migratorios internos dentro del país, la raza afloró como punto de escisión dicotómica, no tan tolo como una diferencia marcada de clase; las "lamentaciones de mendigos" implicaban pertenencia a aquel segmento desmejorado, objeto de vigorización. A este punto se suma la contraparte, el segmento racial del cual sentía pertenencia; la virtuosa y viril raza chilena.

A lo largo de este discurso, hizo una distinción entre "trabajo intelectual" y "trabajo muscular". Para el senador, el trabajo intelectual contribuía a elevar la eficiencia de trabajo muscular. El trabajo muscular, a su vez, era divisible en dos factores, capacidad y acción, donde "capacidad es el número de hombres que trabajan; el factor acción es el rendimiento, la velocidad y la eficiencia con la cual trabajan" (E. Cruz-Coke, "Creación de capitales" 22). Esta conjugación entre calidad de la constitución individuales y cantidad de trabajadores, proyectados como eficiencia, fue trascendental en su visión de la producción de riqueza, "este factor es para nosotros el más importante. Depende de la salud, de la disciplina moral y de la capacidad técnica de cada trabajador" (E. CruzCoke, "Creación de capitales" 22). La base estadística con la cual planteó esta discusión fue la obtenida entre 1937 y 1938 durante la puesta en marcha de la Ley de Medicina Preventiva, insistiendo en que el obrero chileno promedio dejaba de trabajar 12 semanas anuales por concepto de "pasividad transitoria"; pérdida de potencial productivo que significó uno de los argumentos para desarrollar aquel programa de medicina dirigida, en un rol que "rectifique la orientación de los deseos de nuestra gente y los haga agentes de consumo" (E. Cruz-Coke, "Creación de capitales" 23). Independiente del paulatino impacto de la Ley de Medicina preventiva, aparecía una continuidad en su planteamiento sobre las causas y consecuencias, que vinculaban cuerpo mórbido, la compra de reposo y su necesidad de intervención para la creación de una industria nacional.

Respecto a la necesidad de intervención y sus efectos, vale decir, el potenciamiento de una economía industrial, las condicionó a los contextos particulares de desarrollo del liberalismo económico recurriendo a una metáfora organicista; como en un organismo, la intervención tenía sentido en momentos específicos de desarrollo del espécimen: "a una industria naciente o en período 
de crecimiento no se le puede detener su desarrollo sin hacerla morir. A todo lo vivo le pasa lo mismo"; consignando en su discurso que la "industria ha de ser viva para servir al país" (E. Cruz-Coke, "Creación de capitales" 29). Para el caso del senador conservador por Santiago, el modelo de industrialización fue Estados Unidos, sin embargo, voces divergentes en la escena médico-política chilena de aquel periodo, vieron en Alemania y otros países europeos, un arquetipo equiparable bajo las mismas necesidades de injerencia económica y biológica, discrepando en los mecanismos de implementación, no en la necesidad de ella. Dentro de su discurso, explicó de la siguiente manera las relaciones entre Estado y economía, requeridas para posibilitar el despliegue al cual apelaba:

Se refieren al establecimiento de un orden de prelación y de coordinación entre las actividades; a la simplificación cada vez mayor del trabajo y de los intermediarios, a la búsqueda de las metódicas, las más eficientes, señaladas por organismos centrales pero no impuestas; todo en un libre juego que deja a la iniciativa todo su valor, coordinando orgánicamente las funciones, sin unificarlas, para no perturbar su progreso. (E. Cruz-Coke, "Creación de capitales" 43)

Es interesante detenerse en esta referencia, ya que proyecta el tipo de modelo político económico al cual Eduardo Cruz-Coke apuntaba, definiendo roles, sectores y alcances de la intervención del Estado en economía. Aquel orden de prelación naturalizaba el libre juego económico desde la iniciativa privada, dejando al Estado en un papel de coordinación. En el marco de su programa de medicina preventiva, esto posicionaba al aparato público como un garante de la salud de la clase trabajadora en tanto potencial para la economía nacional.

A principios de junio de 1943 realizó en el Senado otra intervención sobre las "exigencias de una gran política nacional" (E. Cruz-Coke, "Exigencias" 5). Frente a la progresión de un modelo de industrialización nacional pensado desde sectores de centroizquierda, disímiles a sus planteamientos políticos, calificó medidas como la fijación de precios de "teóricas y torpes de aparente justicia social", de quiebre económico, disminución de producción y potenciadoras de una crisis inflacionaria. En su discurso la debilidad económica fue representada por "los que no pueden pagar a plazo, los que no tienen casas ni tierra", y operaba dentro de este esquema, como causa en la inestabilidad del intercambio y la perpetuación del patrimonio (E. Cruz-Coke, "Exigencias" 9). En contrapunto, planteó que "un gobernante debe ser un padre para el pueblo y adivinar lo que va a necesitar más tarde" (E. Cruz-Coke, "Exigencias" 10). Su apertura 
económica no solo se reflejó en la proyección temporal, sino que también estaba interrelacionada geoestratégicamente; en sus palabras, "la independencia hay que hacerla funcionar en el concierto de las demás naciones y hacerla útil al progreso y a nuestro afán de trascender la condición humana" (E. Cruz-Coke, "Exigencias" 12). Para resolver estos requerimientos de la política nacional, propuso que los cimientos sobre los cuales debía basarse, eran "el conocimiento de la geografía económica de nuestro país, en su honrada tradición administrativa, en la rica psicología de sus habitantes, en su raza emprendedora". Sin embargo, esta política de dinamización de la producción "debe tener proyecciones continentales" análoga con los logros internos del país (E. Cruz-Coke, "Exigencias" 14). La buena raza ya no solo es viril, sino que también contenía dentro de sí un cariz emprendedor, raza de la cual también era constitutiva una "rica psicología"; todos factores que formaban parte de la geografía económica, legitimando su consideración de la población como un recurso económico.

El 14 de septiembre de ese mismo año, tomó palabra en el Senado para establecer los "Fundamentos de la economía nacional" (E. Cruz-Coke, "Fundamentos de la economía" 45). Sobre la falta de reformas referente a los tipos de actividad económica y al bajo estándar de vida relacionados con las operaciones extractivas, insistió de manera crítica, en que "debiéramos haber ya constituido nuestra economía sobre la industria pesada y la manufactura, haciéndonos arsenal de la América Latina en el más amplio sentido" (E. CruzCoke, "Fundamentos de la economía" 50). En su propuesta, era necesario para Chile hacer una proyección continental considerando "los hechos financieros en gestación para la post-guerra y los elementos de una coordinación internacional implicados en nuestra producción." (E. Cruz-Coke, "Fundamentos de la economía" 50-51). Frente a este panorama, una de las primeras medidas que propuso fue "hacer los esfuerzos necesarios por aumentar esta población activa y no para disminuirla" (E. Cruz-Coke, "Fundamentos de la economía" 67). Durante este discurso, sus esfuerzos estuvieron puestos en establecer una correlación organicista, reiterando una de sus máximas plasmadas en su texto Medicina Preventiva-Medicina Dirigida, para el senador "el trabajo es tan necesario a la vida del hombre como la alimentación". La naturalización del trabajo como necesidad biológica lo llevó a hacer una consideración respecto al tiempo de permanencia del obreros y funcionarios en sus puestos; un llamado a no desperdiciar el potencial que tenía este recurso, buscando una prolongación del mismo en la vida de los trabajadores: "calificar la capacidad funcional por años de servicio, introduce un automatismo cronológico ahí donde ni siquiera se pueden formular leyes biológicas o psíquicas" (E. Cruz-Coke, "Fundamentos de la economía" 69). 
En este escenario, donde había que intensificar, tecnificar y aumentar el tiempo de trabajo en años de servicio, planteó desde su lugar de análisis, que el reparto de las utilidades de las empresas, traducidos en aumento de salario, representaba "el peligro más cierto para la clase trabajadora", ya que en términos de subsidios "aumenta continuamente el volumen de los salarios pasivos con respecto al volumen de los salarios activos" (E. Cruz-Coke, "Fundamentos de la economía" 74). Dentro de su propuesta, la integración de un porcentaje de los pasivos a la población activa, alivianaba la carga económica de las clases populares; no así el aumento de salario. Para el senador, la influencia de las vanguardias políticas europeas de principios de siglo, había llevado a Chile a desarrollar "una política de formas externas, vacías de sentido, que se satisface creando adversarios imaginarios y dándole al pueblo el alimento inasimilable de la discordia", desorientando y despojándolo del "pan sabroso de la verdadera economía social, tal como es y tal como puede ser resuelta" (E. Cruz-Coke, "Fundamentos de la economía" 75). Estos esfuerzos para la tecnificación de la industria no solo estaban planteados en términos de política interna, sino que vistos en perspectiva sobre el desarrollo de una economía basada en la relación con mercados externos, por lo que insistió en la necesidad "de organizar a tiempo un campo de acción sobre todo para la post-guerra, en relación con los planes ingleses y norteamericanos" (E. Cruz-Coke, "Fundamentos de la economía" 79).

Reconoció la necesidad de insumos para su ejecución, algo que desde su perspectiva, solo se podía responder mediante crédito externo, ya que Chile "no puede vivir sin petróleo ni puede desarrollarse sin maquinarias"; ciclo de endeudamiento que justificó como un requerimiento para generar tecnificación y así romper la barrera primario-exportadora (Cruz-Coke, "Fundamentos de la economía" 81). Así, en este discurso se volvió indispensable desarrollar la industria, "que es la única que puede darle contenido civilizador a este país" (E. Cruz-Coke, "Fundamentos de la economía" 85), por lo que planteó una forma de organización "mirando hacia los elementos que mantienen la protección del standard de vida nacional: producción, educación, disciplina social, moralidad civil" (E. Cruz-Coke, "Fundamentos de la economía" 89). Se pronunció activamente sobre el problema de la inflación y propuso la necesidad de limitar "la capacidad de comprar de la ciudadanía" procurando la "detención del alza de los salarios", la aplicación de "impuestos al consumo" y la "restricciones de venta a plazo" (E. Cruz-Coke, "Fundamentos de la economía" 95), a lo que "mejorar el rendimiento del trabajo es contribuir a la producción de riqueza" (E. CruzCoke, "Fundamentos de la economía" 96). Es sugestiva la forma como relacionó mayor cantidad de trabajo con menor capacidad adquisitiva, lo que brinda un espacio importante a la capitalización de la clase trabajadora, marcando una 
tendencia sobre el tipo de política frente al trabajo que perseguía. Este proceso fue concebido "a través de una idea en marcha que discipline moralmente a la ciudadanía y la ponga en trance de ejecutar lo que sea necesario" (E. CruzCoke, "Fundamentos de la economía" 99), nuevamente un requerimiento moral de aplicabilidad económica.

Durante marzo de 1944, Eduardo Cruz-Coke Lassabe dictó una serie de conferencias en la Escuela de Altos Estudios Internacionales de la Universidad de Princeton, Nueva Jersey, las cuales resultan ilustrativas en su percepción de las características constitutivas de una economía "naciente" como la chilena, versus una economía "adulta" como la de Estados Unidos. Explayó sus consideraciones respecto a los rasgos diferenciados que, en aquel momento, concebía como dicotomías inexorables entre América Latina y América del Norte acerca de un potencial industrializador:

El primero consiste en una diferencia de colonización. Mientras la colonización en el norte, fue anglo-sajona, sabemos que en el sur fue de preferencia española y latina. Como los países que se entregaron a la primera estaban poco poblados y los enlaces entre indígenas y colonos eran poco frecuentes, no se jugó en estos suelos la aventura racial de cruzamiento con las poblaciones nativas. Se trató sólo de una trasplantación de los mismos gérmenes, a otra tierra, muy semejante climáticamente a la tierra de origen de los recién llegados (...) otra cosa sucedió en la América Ibérica, en donde el español, al hacer vida común con sus pobladores, le regaló al Continente un nuevo aspecto demográfico (E. Cruz-Coke, "Anatomía y fisiología" $310)$.

Para el senador, el mestizaje entre europeos e indígenas subsumió a los países latinoamericanos en la parte baja de una escala evolutiva de naciones, error que los colonos anglosajones no habrían cometido, preservando lo que él interpretaba como conservación de la pureza racial, factor que interpelaba tanto a las constituciones fisiológicas como conductas morales, en aquellos dos territorios diferenciados por este factor. El ambiente no quedó fuera como elemento en la conformación de los individuos, territorio y población fueron puntos que el senador señaló como determinantes de la divergencia en materias de producción industrial tecnificada, entre países latinoamericanos y la unificación confederada estadounidense, haciéndolo parte de la construcción de estados nacionales en América Latina. El efecto económico del determinismo geográfico apareció en este discurso desde la lectura endocrinológica, haciendo de la temperatura y sus 
efectos en la secreción hormonal, un problema en el proceso de industrialización latinoamericana, "Sabemos que el calor deprime la glándula tiroides y que el frío la estimula; y sabemos cuánta influencia ejerce esta función en el metabolismo cerebral y por lo tanto, en el condicionamiento de los reflejos y en la actitud hacia la iniciativa" (E. Cruz-Coke, "Anatomía y fisiología" 311). Con miras al desarrollo de una economía manufacturera, extendió esta perspectiva en las predisposiciones fisiológicas sobre la producción e innovación:

El frío obliga al hombre a vivir abrigado en un ambiente constante y de esa manera lo coloca en condiciones que favorecen su vida interior y la diversidad de su creación. El calor, la luz, la exuberancia de la naturaleza le imponen en cambio una vida exterior y facilitan la dispersión de sus tendencias que lo hacen juguete de la inconstancia de los elementos (E. Cruz-Coke, "Anatomía y fisiología” 312).

Esta percepción de las diferencias geográficas y raciales, plantean un marcado acercamiento entre el pensamiento de Cruz-Coke y el determinismo biológico, en cuanto lo integró a su interpretación de la población; también como una parte fundamental de la acción médica preventiva y dirigida. Para el senador "tres hechos geográficos proyectan un molde desconcertante a la gente que habita la América morena; un mar, el más caliente; un río, el más ancho; una cordillera, la más alta" (E. Cruz-Coke, "Anatomía y fisiología" 314). América latina, ibérica y morena, todas acepciones propuestas en oposición a la conservación de la pureza anglosajona del norte; la América morena fue la América mestiza, cuadro general de la población chilena: "Herencia y medio se confabulan de esa manera en américa para crear dos tipos de psicología", este hecho para él va a tener consecuencias palpables, tanto en materia económica como en la organización de la sociedad (E. Cruz-Coke, "Anatomía y fisiología" 314). El comportamiento social frente a la producción, para CruzCoke, estuvo determinado por estas variables, lo que justificó la intervención desde posibilidades técnicas, para corregir comportamientos o carencias físicas necesarias para la mejor reproducción de la fuerza de trabajo: "el hombre es un animal que posee la facultad de modificar indefinidamente su ambiente y por medio de esta modificación variar el mismo" (E. Cruz-Coke, "Anatomía y fisiología" 315), cobrando sentido modificar el medio para modificar la conducta.

El posicionamiento del senador Cruz-Coke, sobre las consideraciones político-económicas respecto del avance de la centroizquierda, negaba la socialización de los recursos y la mejora de salario como camino para la superación de la clase trabajadora; por el contrario, implicaba adaptar la población 
al trabajo industrial, donde el cuerpo y voluntad de los trabajadores debían ser puestos al servicio de la economía (E. Cruz-Coke, "Anatomía y fisiología" 319). En este punto cabe recalcar, que aquella economía perseguida por el senador en su discurso, se encontraba proyectada por un orden global específico y requería de un posicionamiento estratégico de Chile en el concierto de las demás naciones, posicionamiento en el cual se hacía inminente ampliar la base de población activa, regenerando a aquellos cuerpos desmejorados para la industria, entendidos como "hombres máquina". En su exposición, el desarrollo latinoamericano estuvo supeditado a la habilitación técnica que hicieran las naciones de más edad, lo que permitiría elevar el estándar de vida, pero por otro evitar el bloqueo, localizándose de manera estratégica frente a las potencias en aquel contexto:

Chile es un país que por su raza y su tradición, sus esfuerzos por involucrarse a costa de muchos sacrificios en la civilización, no quiere resignarse a un destino de colonia, es decir, de país productor de materias primas, más precisamente digamos de materias obtenidas por medio de un trabajo mal remunerado. Por otra parte, no quiere recibir la civilización como un regalo, sino obtenerla como precio de un esfuerzo y conquista por sí mismo (E. Cruz-Coke, "Anatomía y fisiología" 321).

Raza, territorio y cultura, caracteres definidos por el medio y la herencia, durante este discurso, legitimaron tanto su percepción de la independencia, como su apelación al desarrollo de una economía global. Implicó también una reivindicación de la tecnificación industrial como herramienta de supresión del movimiento reivindicativo de clase, en tanto que se adaptaría a su capacidad un trabajo más rentable, apaciguándolo con una reorganización pecuniaria. CruzCoke consideró que aquella "política de buena vecindad", debía basarse en la fortaleza que pudieran tener las naciones independientes, entendiendo esta independencia como "justa y digna interdependencia". En su consideración económica desprende una continuidad en la significación de la intervención médico-social, en una lógica de economía global; incidir en la calidad racial mestiza y asegurar la mejora constitucional por la obtención del beneficio económico, lo que posibilita justificar el colonialismo como un fenómeno natural entre naciones superiores e inferiores:

El signo más auténtico del poder, así como de la riqueza, es la capacidad de crear poder y riqueza. Por lo demás, el único camino de que dispone una gran nación para continuar su progreso es ir 
creando a su alrededor, en naciones menores, las condiciones que lo alimentan, que no pueden ser otras que el progreso de ellas también (E. Cruz-Coke, "Anatomía y fisiología” 326).

A finales de agosto de ese mismo año, el senador por Santiago intervino una de las sesiones de la cámara, con el fin de hacer "Proyecciones de la política y economía chilenas en la post-guerra" (E. Cruz-Coke, "Proyecciones" 101), donde desarrolló su percepción interna de la nación en su incorporación "a un nuevo mundo" (E. Cruz-Coke, "Proyecciones" 103). Esta integración requirió de maquinaria y de reorganización del trabajo asalariado desde la capacidad obrera "para que su rendimiento pueda competir con el rendimiento de las industrias extranjeras" (E. Cruz-Coke, "Proyecciones" 118). Para alcanzar ese nivel de provecho, buscó un "mayor estímulo para trabajar más y mejor y no aumentar los gastos de vicios: carreras, alcohol, tabaco, que representan en Chile mil millones de la renta nacional" (E. Cruz-Coke, "Proyecciones" 125), apelando nuevamente a la creación de una conducta moral de la clase trabajadora en materias de gasto y capitalización individual.

Al agrupar todos los factores anteriores como inherentes al cálculo del riesgo sobre la producción, planteó otra continuidad con su proyecto del año 1938, "De allí también que hayamos establecido para los fines de una discriminación necesaria, diferencia entre previsión biológica y previsión financiera" (E. CruzCoke, "Proyecciones" 126). En este momento se hace clave aquella distinción, ya que han operado históricamente como un soporte de la figura de Cruz-Coke, como padre fundador de un sistema enfocado en lo social y no en lo económico. Lo importante aquí es hacer el seguimiento de la compenetración entre ambas esferas en una sola, donde la previsión biológica, en tanto búsqueda de un biotipo de trabajador, estaba entablada como una forma de resguardo económico sobre el riesgo que implicaba, a su parecer, el azar biológico constitutivo de aquella clase trabajadora, atravesada por caracteres raciales desmejorados, procurando generar en ella un trance de consumo y producción. Es visible la propuesta como un programa integrado de funciones políticas sobre el cuidado del riesgo que representa la población para la economía como factor en la creación de riqueza; "mantener al padre, al abuelo, al sostén de la familia, como cuestión previa. No hacerlo es desencadenar una serie interminable de males sociales desde el punto de vista biológico" (E. Cruz-Coke, "Proyecciones" 132). La preocupación de su "previsión biológica" estuvo enfocada en corregir, de manera anticipada y desde la seguridad social, la aparición de males del cuerpo obrero respecto a su rol de clase. La mantención de esta cadena de interrelaciones económicas en la vida familiar fue uno de sus fundamentos médico-sociales, como una apelación a las 
consecuencias económicas de mala administración científica de la cuestión social. Asimismo, planteó que era preciso que los trabajadores "adquieran conciencia de que las leyes que rigen la economía son leyes tan positivas como las que mandan la circulación de la sangre o el curso de los planetas" (E. Cruz-Coke, "Proyecciones" 133), naturalizando aquel modelo desde un enfoque económico en perspectiva científica. Esto invita a pensar el proceso, como una afirmación del sistema pensamiento experimental aplicado a escala política, lo que permitió hacer hincapié en la naturalización de la administración científica de lo social, planteada orgánicamente:

Es necesario que adquiramos, de una vez por todas, en cuanto a la producción se refiere, la concepción de que las naciones tienen todas las características de un organismo; nacen, se desarrollan y hasta pueden morir, que es así como llamo la pérdida de la independencia a la que llegan los países que contravienen las leyes económicas y biológicas de su supervivencia (E. Cruz-Coke, "Proyecciones" 134).

Uno de los objetos que tuvo la oportunidad de exponer en el cumplimiento de estas leyes económicas y orgánicas, fue la de "crear un poder consumidor en nuestra masa de trabajadores agrícolas, que constituyen la parte más importante de nuestra población obrera", lo que puso como tarea "de educación y cultura unida a un mejoramiento técnico de nuestras tierras y una justa distribución de sus utilidades" (E. Cruz-Coke, "Proyecciones" 137). Aumentar la capacidad de compra representó la posibilidad de generar un cambio en el posicionamiento geoestratégico de Chile dentro de una economía internacional enfocada a las potencialidades de cada territorio. En este posicionamiento global por el cumplimiento de las metas de mímesis desarrollista, para el senador "sería lógico y elemental, por ejemplo, que Chile, que tiene preferencia a una geografía industrial, más que agrícola, fuera el arsenal de productos de acero y cobre" (E. Cruz-Coke, "Proyecciones" 137).

El paso del tiempo y su mayor presencia política afianzaron su enfoque. El domingo 5 de mayo de 1946, durante una concentración del Partido Conservador en el Teatro Central de Concepción, el recientemente proclamado candidato presidencial pronunció un discurso sobre "Política social y económica" (417). Desde esta nueva plataforma, en carrera por el poder ejecutivo, planteó la gestión administrativa de los dos últimos gobiernos del Frente Popular como de abandono frente a los diversos factores enunciados a lo largo del texto, de carácter intrínsecos a su propuesta. En su alocución, la discrepancia se dio "porque [durante los últimos gobiernos frente populistas] no pudieron encontrar 
alguna exigencia espiritual común que las sostuviera, ni, en su reemplazo, equipo que sostuviera sus promesas" (E. Cruz-Coke, "Política social" 419). En su apreciación del momento político internacional, "al atravesar la más grande revolución de los tiempos modernos, en lugar de acentuarla, hemos disminuido nuestra personalidad nacional" (E. Cruz-Coke, "Política social" 419). Por oposición, expuso la reorientación que implicaba su programa presidencial: "Frente al nacimiento de un nuevo espíritu de convivencia y al margen de las tentativas hechas para formularlo, hemos respondido tímidamente al llamado de la historia que nos obliga a desempeñar un papel rector en américa" (E. CruzCoke, "Política social" 419).

Las marcadas diferencias entre su propuesta y la de los gobiernos anteriores, acerca de la implementación de un modelo orgánico durante los años anteriores, se hicieron explícitas. Aglutinadas en un proyecto de industrialización, a los ojos del candidato, la promesa del Frente Popular representaba un lastre para el progreso nacional, a lo que su programa respondió como un repositorio "capaz de asimilar todo lo sano, lo limpio, lo justo, lo decente que haya en todos los partidos" (E. Cruz-Coke, "Política social" 423). Para Cruz-Coke, la carrera a la presidencia simbolizó una posibilidad de dirigir a la nación haciendo extensivos los fundamentos de una medicina y una economía orientadas a nivel general.

Por eso he aceptado esta candidatura presidencial que ha puesto en mis manos el Partido Conservador; por eso, con los míos, hemos aquí tratado de darle todo el contenido que me mandan vuestros anhelos y me exigen mis razones de vivir. Por eso quiero gritarles a todos aquí, inmaculadamente, que nada ya podrá detener esta carrera destinada a hacer que Chile, hoy día empequeñecido, vuelva a entrar a la Historia para dirigir, orientar e iluminar América (E. Cruz-Coke, "Política social" 423).

Desde 1943, el rol preponderante de Chile frente a un escenario económico de interdependencia y la potencialidad de transformar al país en el "arsenal de América", a través de la organización política de una industria manufacturerametalúrgica, estuvieron presentes como finalidad de un programa con vías plausibles de volverse sistemáticas como principios de gobierno. A lo largo de este discurso, propuso un principio categórico en su manera de plantear el ejercicio democrático, "para hacer de veras democracia necesitan sostenerse en el mundo económico sobre las dos columnas de la seguridad social y del crédito" (E. Cruz-Coke, "Política social" 426). Esta interpretación sostuvo la perpetuación de estos factores como principios políticos orgánicos, ya que "la 
seguridad social hecha previsión social proporciona al hombre el metabolismo mínimo para que pueda ser objeto de derecho en la realidad social contemporánea" (E. Cruz-Coke, "Política social" 426). Por otra parte, el crédito, "que permite disponer de la propiedad de terceros y así nos hace a todos solidarios, tiene por función abrir a la persona, al grupo o a la nación, las puertas de la libertad en el terreno económico." (E. Cruz-Coke, "Política social" 427). La capacidad de crédito apareció dentro de sus fundamentos como posibilidad económica para la mejora de las cualidades de la población respecto de una política general del trabajo, el despliegue de esa capacidad desde el sistema económico solucionaba el problema de los focos reivindicativos; una respuesta a la mantención de salarios según las capacidades, el trabajo y la cultura, ya que el crédito como pilar de la democracia, "no puede desenvolverse en un mundo económico que no está penetrado a su vez de un mundo moral, porque el crédito exige confianza". $\mathrm{Su}$ discurso durante la congregación del partido en Concepción, se focalizó en estipular "los fundamentos de un seguro social nacional" (E. Cruz-Coke, "Política social" 430). Para el candidato:

La masa que trabaja debe asegurar la vida y la salud de la masa que por alguna razón no puede trabajar. La capitalización en este sistema no debe ser otra cosa que un mecanismo destinado a amortiguar las fluctuaciones que debido a catástrofes, epidemias o cesantía obligada, alteren la normal relación entre los pasivos y los activos que existen en el país. A diferencia de una compañía de seguros particular, el capital de una seguridad social nacional está constituido por la salud de los activos que trabajan y proporciona los intereses de esta singular sociedad; y por los niños que al pasar al estado adulto, representan un incremento de ese capital. No se trata, como se ve, de una compañía de seguros más grande, con más clientes, sino que se trata de una compañía de seguros de naturaleza diferente que corresponde a un distinto concepto de seguridad (E. Cruz-Coke, "Política social" 430).

\section{CONCLUSIONES}

Con el fin de dar cierre a este ejercicio de relectura, sería conveniente recapitular algunos puntos centrales a modo de síntesis. La representación histórica hecha de la figura de Eduardo Cruz-Coke Lassabe parece desvanecerse en dos personajes completamente distintos, posicionados diametralmente uno 
del otro. El primero de aquellos perfiles, trazado por los autores mencionados en el arranque de este pasaje, permanece alejado del funcionalismo económico, distante del determinismo biológico y del pensamiento racial, renuente a la sobre burocratización y al nacionalismo como parte de su repertorio. Aquella imagen diverge de lo trazado en las páginas anteriores, donde se puede ver a un ministro, un senador y un candidato presidencial, dispuesto a implementar programas de carácter nacional que interpelasen minuciosamente a la clase trabajadora, más allá de una pura consideración productiva, sino que relevando su rol como agentes de consumo. Mediante la revisión de sus textos y discursos políticos, fue posible identificar diversas formas conductuales, que representaron necesidades morales y económicas para brindarle operatividad a la base legal de su fórmula preventiva. Esto permite no solo posicionarlo en un encuadre político, sino hilvanar aquello con escuelas de pensamiento científico que amparaban un accionar determinado. La naturalización de aquellas conductas en sus textos y discursos, requeridas frente a su lectura política en los procesos de salud/enfermedad, exteriorizó el significado de sus prácticas. La sutileza desplegada para transitar hacia la pesquisa de supuestos sanos, sobre las formas con las cuales se emprende la búsqueda, fue un factor determinante en su propuesta preventiva.

Durante este transcurso, ocho años pasaron desde la promulgación de la Ley No. 6.174 de Medicina Preventiva, tiempo en el cual Eduardo Cruz-Coke pudo focalizar su perspectiva económica, en vista a lo que consideraba como necesidades para el desarrollo nacional, presentando en 1946, una concreta expansión hacia una economía dirigida como futuro programa de gobierno. El programa de "conversión de la acción médica" propuesto en 1938, representó una iniciativa de protección biológica de la economía, focalizada en la prevención de enfermedades, como forma de control sobre el riesgo latente que representaban las constituciones individuales pauperizadas, para un sistema basado en el consumo de bienes. Este giro se pudo dar en base a la transformación de los servicios de atención primaria, dispuestos por el Seguro Obrero Obligatorio, en recolectores de datos estadísticos, con el fin de generar una identificación temprana del mal no visible, previa al desencadenamiento de enfermedades que afectasen el mundo del trabajo de manera perniciosa. Al mismo tiempo vio al Estado como una gran compañía de seguros, administradora del riesgo biológico que representaba la población obrera, y posicionó la capacidad de crédito como garante del estándar de vida, en oposición a las reformas salariales.

La modificación de la política de seguros sociales planteaba una vía sólida para la implementación de este programa, sobre un universo que contemplaba prácticamente la totalidad de los activos del país. Esencialmente aquellos eran el segmento de la población, que en la perspectiva de Cruz-Coke, tenían que ser 
recuperados primero. Este punto es posible de ser articulado como argumento para pensar este programa de "conversión de la acción médica" como un programa general de medicina del trabajo, y dirigido a una clase en particular, que padecía de enfermedades problemáticas para el desarrollo del modelo de economía industrializada que este médico pretendía para Chile; una de carácter civilizador. Eduardo Cruz-Coke focalizó su programa preventivo en el supuesto sano, puesto que aquella morbilidad oculta y latente, para él significaban un tipo de riesgo más específico a combatir desde la administración pública de la salud, para alcanzar las metas desarrollistas de mímesis con las metrópolis europeas y norteamericanas.

En este proceso, su acercamiento a agentes de eugenesia, como la figura del profesor Noé y la de Nicola Pende se vuelven trascendentales, ya que le ofrecieron un marco más eficiente y focalizado de pesquisa sobre la población económicamente activa, y un modelo de identificación aplicable en distintos escenarios, ya no solo aplicado al riesgo de criminalidad como lo planteaba Pende, en un sentido más estricto, dado por lo endocrino, sino una metodología de identificación del anormal riesgoso parametrizado con un sentido económico determinado. Su propuesta diferenciada de "previsión biológica" estuvo planteada como una acción protectora ejercida desde la salubridad sobre la economía y no en el sentido opuesto.

Es necesario también situar en sus alocuciones y escritos, la presencia de factores biológicos y el rol que estos desempeñaban, al momento de plantear las funciones tuvo la organización de un sistema de salud en correlación con el riesgo económico. Aquello evidencia una serie de causas y consecuencias en su lectura del sentido y el deber de la medicina social en Chile. Esta perspectiva estaba proyectada sobre un escenario global, con reglas definidas por el contexto de posguerra, donde la clase trabajadora fue considerada, al mismo tiempo, como un peligro latente y un potencial susceptible de mejora. La propuesta de medicina preventiva hecha por Eduardo Cruz-Coke Lassabe buscó corregir los estados patológicos en la población económicamente activa de manera anticipada a su manifestación última, en un orden verticalizado y paternalista. Dentro de este esquema, reparar al hombre máquina implicó, para él, regenerar a la masa trabajadora para adaptarla al trabajo industrial y no hacer una mejora de sus condiciones históricas de clase. Esto operó como una naturalización biológica de la desigualdad ya que puso los esfuerzos en la protección del sistema económico y no en la población como objeto de ese sistema. Reparar esa máquina comprometió también regenerar a la masa trabajadora, considerada como un segmento desmejorado de la raza chilena, de acuerdo a los valores que interpretaba como constitutivos de los mejores exponentes de aquella, dentro 
de los cuales se sentía perteneciente. Algunos de aquellos fueron la virtud, la virilidad, el emprendimiento, la disposición al trabajo, disciplina social, moralidad civil y la cultura del ahorro. Este replanteamiento de los factores dice relación con la búsqueda por generar mayor eficiencia nacional.

En referencia a este último punto, entendió el aumento de subsidios como un obstáculo para la generación de población económicamente activa, enunciando que solo contribuía al incremento de pasivos a nivel nacional, lo que le permitió desplegar el concepto de "pasividad transitoria", que terminaría siendo una de sus motivaciones y fundamentos médico-sociales. En ese mismo camino, la búsqueda por crear una sociedad de consumo desde lo biológico se justificó con fin de establecer a Chile, en un papel rector dentro de la lógica continental, como arsenal de América Latina e insertarlo en las lógicas de un mercado mundial. Aquel nuevo "aspecto demográfico" expuesto en 1944 como producto del mestizaje entre colonos y colonizados, lo llevó a posicionar de manera vertical a ambos polos del continente americano en una escala evolutiva; oposición maniquea dispuesta desde el parámetro de la pureza racial en la que también amparó una legitimación histórica del colonialismo. Con la forma de un programa global de bio-economía, las variables raciales, así como el territorio y la cultura, jugaron un significativo papel en la conformación en su visión de las poblaciones en uno y otro hemisferio. Para el senador, el ambiente latinoamericano objetiva a la población como un mero juguete de la inconstancia de los elementos, recalcando la importancia de este componente en la producción física y moral de los habitantes de estos territorios. Al mismo tiempo, este factor posibilita la iniciativa interventora, sobre una población racialmente desmejorada producto del mestizaje, lo que indica una presencia activa del pensamiento lamarckiano en sus posturas.

Eduardo Cruz-Coke generó un legado como potenciador de un ciclo entre investigación científica, pedagogía, universidades, militancia, ministerios y el senado, llegando a consolidarse como uno de los gestores de políticas públicas en torno a la salud más relevantes de la primera mitad del siglo XX en Chile. Operó como un engranaje entre medicina y economía, que amerita mayor análisis tanto desde la historia política como de las prácticas científicas. Esta relectura solo se abocó a tensionar parte de su obra, posicionamiento que pretende abrir las posibilidades para interpretaciones futuras respecto a la producción de pensamiento político desde lo científico. Al agregar variables al relato histórico, más allá del debate internalismo-externalismo, se puede leer una correlación entre escuelas de pensamiento científico y la producción de políticas públicas; factores inexpugnables en el proceso de dotar de significado a una práctica política relativa a la proyección de un modelo social configurado 
desde lo biológico, demostrables en base a leyes universales. En momentos de la historia como los que experimentamos actualmente, donde el modelo neoliberal pone a prueba de manera manifiesta los alcances de la Salud Pública y las labores preventivas a nivel global, cobra importancia hacer una revisión crítica sobre sus cimientos en esta materia, evaluando las causas y consecuencias de su institución y funcionamiento.

\section{REFERENCIAS BIBLIOGRÁFICAS}

Álvarez Peláez, Raquel. Sir Francis Galton, padre de la eugenesia. Cuadernos Galileo de historia y ciencia, CSIC, 1985.

-----. "Eugenesia, ideología y discurso del poder en España". Darwinismo Social y Eugenesia en el Mundo Latino, compilado por Marisa Miranda y Gustavo Vallejo, Siglo XXI, 2005, pp. 87-114.

Berger, Peter y Thomas Luckmann. The social construction of reality. Amorrortu Editores, 1994.

Cruz-Coke, Eduardo. Tuberculosis y Vagotonismo. Imprenta y encuadernación La República, 1921.

-----. La Acidez Iónica en Clínica. Imprenta Chile, 1925.

-----. Medicina preventiva-medicina dirigida. Editorial Nascimiento, 1938.

----- La corteza supra-renal. Química-fisiopatología-clínica. Editorial Nascimiento. 1942.

-----. "Prólogo". Discursos. Política-Economía-Salubridad-Habitación-Relaciones Exteriores-Agricultura. Editorial Nascimiento, 1946, pp. 3-4.

-----. "Creación de capitales nacionales". Discursos. Política-Economía-SalubridadHabitación-Relaciones Exteriores-Agricultura. Editorial Nascimiento, 1946, pp. 17-45.

-----. "Exigencias de una gran política nacional". Discursos. Política-EconomíaSalubridad-Habitación-Relaciones Exteriores-Agricultura. Editorial Nascimiento, 1946, pp. 5-16.

-----. "Fundamentos de la economía nacional". Discursos. Política-EconomíaSalubridad-Habitación-Relaciones Exteriores-Agricultura. Editorial Nascimiento, 1946, pp. 45-101.

-----. “Anatomía y fisiología de una política de buena vecindad”. Discursos. PolíticaEconomía-Salubridad-Habitación-Relaciones Exteriores-Agricultura. Editorial Nascimiento, 1946, pp. 307-330. 
-----. "Proyecciones de la política y economía chilenas en la post-guerra". Discursos. Política-Economía-Salubridad-Habitación-Relaciones Exteriores-Agricultura. Editorial Nascimiento, 1946, pp.101-160.

-----. "Política social y económica". Discursos. Política-Economía-SalubridadHabitación-Relaciones Exteriores-Agricultura. Editorial Nascimiento, 1946, pp. 417-448.

Cruz-Coke, Ricardo. "Historia de la obra científica de Eduardo Cruz-Coke Lassabe". Revista médica de Chile, vol. 129, no. 4, 2001, pp. 447-455. https://doi.org/10.4067/s0034-98872001000400015

Comisión organizadora. Circular general. Congreso Nacional de Alimentación Popular. Ministerio de Bienestar Social, vol. 461, Archivo Nacional de la Administración, 1930.

Foucault, Michel. Un diálogo sobre el poder y otras conversaciones. Alianza Editorial, 1988.

-----. Historia de la sexualidad. I. La voluntad del saber. Gallimard, 1976.

Galera, Andrés. "Hacia una fisiología del delito: el modelo biotipológico de Nicola Pende". Darwinismo Social y Eugenesia en el Mundo Latino, compilado por Marisa Miranda y Gustavo Vallejo, Siglo XXI, 2005, pp. 363-374.

-----. "La escuela criminológica italiana. Determinismo y patología del delito". Políticas del cuerpo. Estrategias modernas de normalización del individuo y de la sociedad, compilado por M. Miranda y G. Vallejo, Siglo XXI, 2007, pp. 131-138.

Haraway, Donna. "Situated knowledges: the science question in feminist as a sit of discourse on the privilege of patriarchal perspective". Feminist studies, vol. 14, no. 3, 1998, pp. 575-599. https://doi.org/10.2307/3178066

Huneeus, Carlos y María Paz Lanas. "Ciencia política e historia: Eduardo CruzCoke y el Estado de bienestar en Chile, 1937-1938”. Historia, vol. 35, 2002, pp. 151-186. https://doi.org/10.4067/s0717-71942002003500007

Kragh, Helge. Introducción a la historia de la ciencia. Crítica, 1989.

Moulian, Tomás e Isabel Torres-Dujisin. "Las candidaturas presidenciales de la derecha: 1946”. FLACSO, no. 339, 1987, pp. 1-151.

Moulian, Tomás. Fracturas. De Pedro Aguirre Cerda a Salvador Allende (19381973). LOM, 2006.

Palma, Héctor. "Consideraciones historiográficas, epistemológicas y prácticas acerca de la eugenesia". Darwinismo Social y Eugenesia en el Mundo Latino, compilado por Marisa Miranda y Gustavo Vallejo, Siglo XXI, 2005, pp. 115-144. 
Rodríguez Ocaña, Esteban. "El Concepto Social de Enfermedad". Historia de la Enfermedad, coordinado por A. Albarracín, Saned, 1987, pp. 341- 349.

Sánchez, Marcelo. "El profesor Juan Noé: Eugenesia y mendelismo en tres décadas de docencia médica en Chile (1913-1947)". República de la Salud. Fundación y ruinas de un país sanitario. Chile Siglos XIX y XX, editado por Claudia Araya et al., Ocho Libros, 2016, pp. 49-73.

Sánchez, Marcelo y Nicolás Cárcamo. "Hans Betzhold y el "superhombre" chileno: historia de una decepción, 1938-1943”. História, Ciências, Saúde - Manguinhos, vol. 25, no. 2, 2018, pp. 51-68. https://doi.org/10.1590/ s0104-59702018000300004

Sánchez, Marcelo. "Alimentación y eugenesia. Aproximaciones desde Chile: 1900-1950." Gobernar es alimentar. Discursos, legislación y políticas de alimentación popular, Chile, 1900-1950, coordinado por Juan Carlos Yáñez Andrade, América en movimiento, 2018, pp. 53-82.

Stepan, Nancy. Hora da eugenia: raça, gênero e nação na América Latina. Editora Fiocruz, 2005.

Toro, Pablo. "La Guerra Santa por el bienestar de la Patria. Social cristianismo y política social: la campaña presidencial de Eduardo Cruz-Coke en 1946". Catolicismo social chileno. Desarrollo, crisis y actualidad, editado por Fernando Berríos et al., Universidad Alberto Hurtado, 2009, pp. 333-353.

Vallejo, Gustavo. "Las Formas del Organicismo Social en la eugenesia Latina". Darwinismo Social y Eugenesia en el Mundo Latino, compilado por Marisa Miranda y Gustavo Vallejo, Siglo XXI, 2005, pp. 231-272. https:// doi.org/10.31819/9783964562661-005

Vallejo, Gustavo y Marisa Miranda. "Los saberes del poder: eugenesia y biotipología en la Argentina del siglo XX." Revista de Indias, vol. 64, no. 231, 2004, pp. 425-444. https://doi.org/10.3989/revindias.2004.i231.547

-----. "Iglesia católica y eugenesia latina: un constructo teórico para el control social (Argentina, 1924-1958)". Asclepio, vol. 66, no. 2, 2014, pp. 55. https://doi.org/10.3989/asclepio.2014.19

Yáñez, Juan Carlos (coord). Gobernar es alimentar. Discursos, legislación $y$ políticas de alimentación popular, Chile, 1900-1950. América en movimiento, 2018.

Zárate, María Soledad. “Alimentación y Previsión Biológica: La política MédicoAsistencial de Eduardo Cruz-Coke" (Estudio introductorio), en Eduardo Cruz-Coke, Medicina preventiva y medicina dirigida, Cámara Chilena de la Construcción, PUC, Biblioteca Nacional, 2012, pp. IX-LXV. 